Chronic cough

\section{Chronic cough - not such a heartsink}

\section{A H Morice}

\section{Knowledge of the pathophysiology of the different conditions which cause chronic cough is vital to achieving a correct diagnosis and successful treatment.}

$\mathrm{P}$ atients present with symptoms. Doctors are trained to recognise disease. There is no better illustration of these two different paradigms than cough. Unfortunately for the patient, the sensory input triggering the cough reflex may arise from anywhere in the territory of the vagus nerve. Thus, chronic cough may be caused by conditions treated by at least three different specialists-the ENT surgeon, the gastroenterologist, and the chest physician. Because of our speciality led view of the world, the doctor may not have received training in the condition causing the symptom. There is a risk of treating the patient for the condition with which the doctor is familiar rather than that most likely to be the cause of the cough. In a recent survey of over 300 patients who had asked for information about chronic cough, most had consulted at least one specialist of whom 69\% were chest physicians. Presumably the treatment had not worked, which is why they needed further information; this suggests an urgent need for greater understanding. For this reason, Thorax has commissioned a review series on the aetiology and treatment of this disabling and socially isolating symptom.
In contrast to experience in general chest clinics, ${ }^{1}$ there is extensive literature to support the very high treatment success rates seen in specialist cough clinics throughout the world, ${ }^{2}$ supporting grounds for optimism. Most of these therapeutic successes are achieved without resorting to sophisticated specialised investigations. The clinical history is the major clue to the diagnosis in chronic cough. However, knowledge of the pathophysiology of the various conditions is vital to understanding these clues. In the differentiation of asthmatic and reflux cough, for example, the diurnal variability of the cough is often sufficient to make the diagnosis. In 1698 Sir John Floyer ${ }^{3}$ first described the still unexplained nocturnal exacerbations of asthma symptoms, and nocturnal cough remains a common symptom of cough predominant asthma. In contrast, a patient with reflux cough will rarely cough at night. Appreciation of this requires a knowledge of the physiology of the lower oesophageal sphincter. ${ }^{4}$ The sphincter closes at night, diminishing reflux and causing the cough to abate. The patient with reflux cough wakes peacefully and not as in Floyer's own graphic description of the morning exacerbation "at first waking the fit takes $\mathrm{me}^{\prime \prime}$. Rather, the paroxysms of coughing start when the patient gets up and the sphincter opens to allow for belching. It is hoped that this series of reviews will provide the reader with valuable clinical pointers to aid in the management of these potentially challenging patients.

In the last two reviews of the series, recent developments in the physiology and pharmacology of cough will be summarised. For many years the term "cough receptor" has been used in what is no more than the description of the type of nerve fibre transmitting the stimulus. In the last few years the first genuine cough receptor-the VRl-has been cloned, and there has been a rapid increase in the basic knowledge of cough receptor function. From this may arise treatments which may be effective in the single most common presenting complaint for which new pr...

Thorax 2003;58:829

\section{Author's affiliation}

A H Morice, Academic Department of Medicine, Respiratory Medicine, University of Hull, Castle Hill Hospital, Cottingham HU16 5JQ, UK; a.h.morice@hull.ac.uk

\section{REFERENCES}

1 McGarvey LPA, Heaney LG, MacMahon J. A retrospective survey of the diagnosis and management of patients presenting with chronic cough to a general chest clinic. Int J Clin Pract 1998;52:158-61.

2 Morice AH, Kastelik JA. Cough - 1: Chronic cough in adults. Thorax 2003:58:901-7.

3 Floyer J. A treatise on the asthma. London, 1698.

4 Mittal RK, Balaban DH. The esophagogastric junction. N Engl J Med 1997;336:924-32.

5 Cullinan P. Persistent cough and sputum: prevalence and clinical characteristics in south east England. Respir Med 1992;86:143-9.

\title{
Pulmonary physicians, intensive care medicine and Thorax: an evolving relationship
}

\author{
$S$ Baudouin, T Evans
}

Intensive care medicine as a separate specialty will impact on the availability of services, training of pulmonary physicians, and the content of respiratory medicine journals such as Thorax.

l n the 1990s a series of well publicised cases, in which critically ill patients were moved large distances in order to gain access to intensive care facilities, led to the recognition that the provision of intensive care services in the UK was characterised by unacceptable variations in organisation and delivery, quantity, funding, and effectiveness. It was appreciated that the ad hoc development of the discipline of intensive care medicine-following its origins in the polio epidemics of the 1950s-was responsible in part for this unhappy state of affairs. However, it was also apparent that there had been years of relative underfunding of intensive care units (ICUs) in the UK compared with other 


\section{Table 1 Classification of illness severity ${ }^{3}$ \\ Level 0 Patients whose needs can be met through normal ward care in an acute hospital \\ Level 1 Patients at risk of their condition deteriorating, or those recently relocated from higher levels of care, whose needs can be met on an acute ward with additional advice and support from the critical care team \\ Level 2 Patients requiring more detailed observations or intervention including support for a single failing organ system or postoperative care and those "stepping down" from higher levels of care \\ Level 3 Patients requiring advanced respiratory support alone or basic respiratory support together with support of at least two organ systems. This level includes all complex patients requiring support for multiorgan failure}

developed societies. The provision of ICU beds in the UK has historically been one of the smallest in the industrialised world. Only $2.6 \%$ of hospital beds were designated for intensive care before 2001 compared with averages of $3.3 \%$ and $5-7 \%$ in Europe and North America, respectively. ${ }^{1}$ Furthermore, in the UK the practice of intensive care medicine was led principally by clinicians with anaesthesia as their base speciality, who were being asked increasingly to provide multiple services across numerous hospital departments ranging from pain relief to supporting day case, high throughput surgery. Many of these issues were recognised in the Audit Commission report of 1999. ${ }^{2}$

By the end of the last decade, many pressure groups and professional bodies within the medical and allied professions-most notably the Intensive Care Society-together with central government recognised that a new multidisciplinary approach to the delivery of critical care services across acute hospitals was desirable. Consequently, in April 1999 the Department of Health appointed a review body tasked with developing a framework for the future organisation and delivery of critical care. The group published its report, "Comprehensive Critical Care", in $2000 .^{3}$ It acknowledged that many of the difficulties faced were both organisational and structural. A number of seminal recommendations emerged, the principal one being that a new approach based upon severity of illness should be used to determine the delivery of service in accordance with the individual needs of the patient, rather than their physical location (table 1). It was agreed that the provision of comprehensive critical care should be defined by a systemically planned and delivered service integrated into a hospital-wide approach, extending beyond the physical boundaries of the intensive care and high dependency units. Networks were to be established between NHS trusts, working to common standards and protocols within geographically defined regions. It was recognised that a planned approach to workforce development was needed, balancing the skill mix between medical, nursing, and allied health professionals such that the most appropriate mix of skills could be brought to bear on specific clinical problems. Finally, the service was to incorporate a culture based on data collection, thereby promoting evidence based clinical care.

Two other relevant reports have since focused attention on the standards of care delivered to acutely ill patients within medical wards. The first was commissioned by the Royal College of Physicians $^{4}$ following the publication of data indicating that the care of severely ill medical inpatients in the UK is frequently suboptimal, implicating poor recognition of the severity of illness by junior clinical staff, a lack of senior medical input, and the slow or inappropriate application of therapeutic interventions. Indeed, one investigation of the quality of medical management prior to ICU admission found it to be unsatisfactory in $54 \%$ of cases. $^{56}$ Mortality in this group was significantly higher than in those managed appropriately in the pre-ICU phase $(48 \% v$ $25 \%$ ). Even more disturbingly, studies of events leading to "unexpected" in-hospital cardiac arrest have indicated that many patients have evidence of marked physiological deterioration clearly recorded before the event without appropriate action being taken. ${ }^{78}$ A key requirement for the increased provision of non-invasive ventilatory (NIV) support services was identified in the report, together with a number of other points relating particularly to the identification of acutely ill patients and the inadequacies of training junior clinical staff.

The second report, by the National Confidential Enquiry into Perioperative Deaths (NCEPOD), has commissioned an investigation of the care of medical patients requiring or developing level 3 dependency. Although the results are still awaited, they are likely to reinforce the impression that suboptimal management of medical inpatients in UK hospitals is not uncommon.
- What has been the impact of these reports on the availability of facilities for patients with increased dependency?

- More specifically, are there implications for respiratory physicians?

- How should a journal such as Thorax recognise the importance of these developments?

\section{IMPACT ON AVAILABILITY OF FACILITIES}

ICU capacity in the winter of 2000 underwent a marked expansion in England with an increase of approximately $22 \%$ in total bed numbers catering for patients with what is now termed level 2 and level 3 dependency. Level 2 bed numbers increased by approximately $50 \%$ and level 3 beds by $8 \%$. This is clearly good news for the critically ill, but issues relating to improved organisation and staffing remain to be addressed. Nevertheless, the Department of Health has recognised the deficiencies in the training of junior medical staff by recommending that all trainees, whatever their intended speciality, should be exposed to a period of training in intensive care medicine. ${ }^{9}$

Thoracic medicine has a key part to play in the delivery of a comprehensive critical care service within all acute trusts. This was recognised implicitly in the report of the Royal College of Physicians Working Group and developed further by the NHS Modernisation Agency subgroup emanating from the expert group producing "Comprehensive Critical Care ${ }^{\prime \prime} .^{10}$ Their recently published report suggested that an NIV service should be established in each acute trust, on the grounds that selected groups of patients with acute respiratory insufficiency have been shown to benefit from this intervention. ${ }^{11}$ Equally importantly, it may be more suited to patients' needs and can reduce the complication rate attributable to endotracheal intubation. The development of such a service would not only facilitate the movement of patients from level 3 to level 2 dependency, but would also afford a more palatable and dignified means of providing respiratory support to those who have little hope of being successfully weaned from mechanical ventilation owing to the chronicity and/ or terminal nature of their pulmonary disease. It was also recognised that NIV should be provided in specialist centres for patients with delayed weaning and for those likely to require long term and domiciliary ventilatory support. 


\section{IMPLICATIONS FOR RESPIRATORY PHYSICIANS}

Respiratory physicians have diagnostic and therapeutic skills particularly relevant to the care of the acutely ill. Thus, respiratory insufficiency represents the most common cause of deterioration for patients likely to require level 3 support, and acute respiratory illnesses represent the second most common reason for Accident \& Emergency consultation in the UK. Furthermore, respiratory physicians already make an enormous contribution to the provision of acute emergency care to patients arriving in acute trusts via the unselected medical take. Thoracic physicians also possess skills that are complementary to those of intensivists with predominantly anaesthetic backgrounds. In particular, they have the experience and resources to provide the often prolonged inpatient care that ICU survivors require once they no longer need the services of critical care. In addition, they are well placed to provide longer term outpatient follow up to this group as recommended in "Comprehensive Critical Care". Finally, respiratory physicians could participate in the care of patients requiring prolonged weaning on the model of North American intermediate care units.

The recognition by the Specialist Advisory Committee for Training in Respiratory Medicine that gaining competency in certain skills relevant to intensive care medicine forms a crucial part of the training programme of all specialist registrars is tacit recognition of the increasingly close ties between respiratory medicine and critical care. Indeed, the recognition that one year of training in intensive care medicine (incorporating experience in anaesthesia) can substitute for an equivalent period in general internal medicine/ respiratory medicine has precluded the need to extend the overall period of training for those seeking recognition of their experience at intermediate level by the Intercollegiate Board for Training in intensive care medicine. Specialty recognition, involving the award of a dual or even triple (general internal medicine, respiratory, intensive care medicine) certificate of specialty training, is now available for those prepared to add a further year to their training programme.

In other countries (notably North America where the vast majority of intensive care facilities are staffed by individuals with training in pulmonary/ critical care), intensive care and respiratory medicine have traditionally been closely linked. This pattern may be adopted increasingly across Europe following the publication of a report by the European Respiratory Society exploring the basis of this relationship. ${ }^{12}$ In summary, recognition that individuals with clinical experience gained in a variety of base specialties have a part to play in the delivery of newly designated critical care services should encourage the participation of respiratory physicians in this increasingly important activity. We would encourage some to become intensivists in their own right, but all should work within the multidisciplinary team to develop and expand the service within the spirit of "Comprehensive Critical Care".

\section{"The new editors of Thorax pledge to pay particular attention to sub- missions . . from . . . acute care and intensive care medicine"}

\section{IMPLICATIONS FOR JOURNALS IN RESPIRATORY MEDICINE}

So what are the implications of the closer links developing between respiratory medicine and intensive care medicine for journals such as Thorax? We suggest that they are several.

Firstly, many of the key advances in critical care that have emerged in recent years have been related to the investigation and management of patients with acute and chronic respiratory insufficiency. Indeed, the American Thoracic Society's decision in the early 1990s to change the title of the American Review of Respiratory Disease to incorporate critical care medicine is tacit recognition of the growing and increasingly influential scientific base of intensive care medicine. Secondly, it seems reasonable that respiratory physicians should be educated in subjects relevant to the acutely ill patient, especially if up to 6 months of experience for all specialist registrars is to take place within the environs of a critical care service. Moreover, if an increasing burden of responsibility for the provision of acute care, at least for patients with respiratory insufficiency, is to be placed upon our specialty, then the publication of appropriate scientific advances and allied educational initiatives-both features of this publication over the years-should be encouraged. Thirdly, while Thorax remains the journal of the British Thoracic Society, by encouraging submissions from individuals practising within intensive care medicine with non-respiratory base specialties, the breadth, interest and circulation of the journal and its impact on clinical practice will be augmented. Fourthly, recognition that acute illness will represent an ever escalating burden upon the NHS should lead investigators and scientists to address the problems of the critically ill with ever increasing urgency. Indeed, we suggest that relevance of research to the needs of stakeholders-the patients we servewill become an issue of increasing importance to the research councils and charitable bodies in deciding on the allocation of their scarce resources. Finally, and possibly most important of all, intensive care medicine is exciting and very broad based. Legitimate areas of investigation range from genetic predisposition to critical illness through the cellular aspects of the pathophysiology of the inflammatory response (manifest in sepsis, the systemic inflammatory response syndrome, and their sequelae) to complex economic and ethical issues.

We are privileged to report that the new editors of Thorax pledge to pay particular attention to submissions (scientific, clinical, and reviews) emerging from the fields of acute care and intensive care medicine. Not surprisingly, we applaud this initiative and hope that it leads to an expansion of the scientific and clinical base of a newly recognised specialty that will bring together multiple disciplines in a novel and exciting fashion.

Thorax 2003;58:829-832

\section{Authors' affiliations}

S Baudouin, Senior Lecturer in Intensive Care Medicine, Royal Victoria Infirmary, Newcastle upon Tyne, UK

T Evans, Professor of Intensive Care Medicine, Royal Brompton Hospital, London, UK

Correspondence to: Professor T W Evans, Royal Brompton Hospital, London SW3 6NP, UK; t.evans@rbh.nthames.nhs.uk

\section{REFERENCES}

1 Edbrooke D, Hibbert C, Corcoran M. Review for the NHS Executive of adult critical care services: an international perspective. Sheffield: Medical Economics and Research Centre, 1999)http:// www.doh.gov.uk/pdfs/ccperspective.pdf.

2 Audit Commission. Critical to success. The place of efficient and effective critical care services within the acute hospital. London: Audit Commission, 1999; http://www.auditcommission.gov.uk.

3 Department of Health. Comprehensive critical care. A review of adult critical care services. London: Department of Health, 2000; http:// wuw.doh.gov.uk/nhsexec/compcritcare.htm.

4 Royal College of Physicians. The interface between acute general medicine and critical care. London: Royal College of Physicians, 2002.

5 McQuillan P, Pilkington S, Allan A, et al. Confidential inquiry into quality of care before admission to intensive care. BMJ 1998;316:1853-8.

6 McGloin H, Adam SK, Singer M. Unexpected deaths and referrals to intensive care of patients on general wards. Are some cases potentially avoidable? J R Coll Physicians Lond 1999;33:255-9.

7 Franklin C, Mathew J. Developing strategies to prevent in-hospital cardiac arrest: analyzing responses of physicians and nurses in the hours before the event. Crit Care Med 1994;22:244-7.

8 Schein RM, Hazday N, Pena M, et al. Clinical antecedents to in-hospital cardiopulmonary arrest. Chest 1990;98:1388-92. 
9 Department of Health. Unfinished business: proposal for the reform of the SHO grade-a paper for consultation. London: Department of Health, 2002; http://

www.doh.gov.ukshoconsult/shoreport.pdf..

10 National Patients Access Team Critical Care

Programme. Weaning and long term ventilation.
London: Department of Health, 2002; http://www.modern.nhs.uk/criticalcare/ 5032/5195/

weaning and ventilation report.pdf.

11 Plant PK, Owen JL, Elliott MW. Early use of non-invasive ventilation for acute exacerbations of chronic obstructive pulmonary disease on general respiratory wards: a multicentre

randomised controlled trial. Lancet 2000;355: 1931-5

12 Evans T, Elliott MW, Ranieri M, et al. Pulmonary medicine and (adult) critical care medicine in Europe. Eur Respir J 2002;19:1202-6.

\title{
Hypothesis: Does COPD have an autoimmune component?
}

\author{
A Agustí, W MacNee, K Donaldson, M Cosio
}

A new hypothesis that considers the role of the immune system in the pathogenesis of COPD is explored which, if true, will generate new therapeutic opportunities in this condition.

C hronic obstructive pulmonary disease (COPD) is a major public health problem because: (1) it causes significant morbidity and mortality which is expected to increase worldwide in the near future; ${ }^{1}(2)$ it jeopardises the quality of life of the patients suffering from this devastating disease (particularly during exacerbations) $;{ }^{3}$ and (3) it imposes an enormous global healthcare cost. ${ }^{1}$ However, because the pathogenesis of COPD is poorly understood, treatment is mostly symptomatic and new therapeutic strategies are limited. ${ }^{4}$ In this paper we propose a new hypothesis that considers the largely unexplored role of the immune system in the pathogenesis of COPD. If true, this hypothesis will generate new therapeutic opportunities in COPD.

\section{THE CURRENT VIEW}

The Global initiative for the diagnosis, management, and prevention of Obstructive Lung Disease (GOLD) defines COPD as a "disease state which is usually both progressive and associated with an abnormal inflammatory response of the lungs to noxious particles or gases". ${ }^{5}$ Many studies have attempted to characterise this abnormal inflammatory response. However, this issue is far from resolved because the results of these studies vary according to the severity of the disease (mild, moderate, or severe), the type of controls studied (never smokers, smokers with normal lung function, patients with stable COPD compared with those studied during exacerbations of the disease), the compartment of the lung sampled (central airways, peripheral airways, alveolar space), and/or the bias of the study towards the role of a given cell type. ${ }^{6}$ A critical review of this literature ${ }^{7}$ indicates the following salient features: (1) all smokers develop airway inflammation; (2) this is amplified in patients with COPD, particularly during exacerbations of the disease; (3) there is a direct relationship between the severity of the disease and the intensity of the inflammatory response; (4) airspace inflammation persists after smoking cessation; (5) all inflammatory cell types (macrophages, neutrophils, lymphocytes, eosinophils, natural killer cells) are implicated in the inflammatory process of COPD; (6) many different mediators released by activated inflammatory cells can damage lung structures; and (7) oxidative stress due to cigarette smoking is important in the pathogenesis of COPD. How all these cells and inflammatory mediators interact and contribute to the disease is presently unclear. Yet, a better understanding of these interactions is mandatory if new therapeutic options are to be developed. ${ }^{8}$

\section{THE QUESTIONS}

In this context, we believe that there are three specific questions of particular relevance.

\section{Why do only some smokers develop COPD?}

Tobacco smoking is the main risk factor for COPD, but not all smokers develop the disease. ${ }^{9}$ Although it is possible that more patients would develop COPD if they did not succumb from other smoking related conditions such as ischaemic heart disease and lung cancer, the fact remains that most smokers do not present with clinically significant airflow obstruction. ${ }^{8}$ If we accept that COPD is associated with an abnormal inflammatory response in the lungs, ${ }^{5}$ we should concede that excessive inflammation is the key to susceptibility. However, the mechanisms underlying this enhanced inflammatory response in susceptible smokers are completely unknown.

\section{Why does inflammation persist after quitting smoking?}

Although relatively small numbers of patients have been studied, several papers have shown that inflammation persists long after the patient has stopped smoking. ${ }^{10-12}$ The mechanism(s) underlying this observation are also unknown, but it clearly indicates the existence of some self-perpetuating pathogenic process, initiated but not necessarily perpetuated by smoking, that prevents the normal resolution of the inflammatory response. ${ }^{13}$ This type of mechanism seems to operate in many autoimmune diseases. ${ }^{14}$

\section{What are the mechanisms of exacerbations of COPD?}

Patients with COPD often present with exacerbations during the course of their disease. These episodes significantly diminish their quality of life, ${ }^{3}$ may require admission to hospital, ${ }^{15}$ and cause significant mortality. ${ }^{16}$ They are characterised by increased airway inflammation. ${ }^{17-19}$ However, the mechanisms causing them are unclear. Normally they are explained on the basis of airway infection (viral or bacterial) and/or the effects of air pollution, ${ }^{20}$ but evidence supporting the former can be found in only $50-60 \%$ of cases $^{21}$ and the latter do not seem to be powerful enough to explain the majority of exacerbations. ${ }^{22}$ Thus, many of these episodes remain unexplained.

\section{LESSONS FROM AUTOIMMUNE DISEASES}

Autoimmune diseases are chronic inflammatory conditions characterised by the loss of tolerance to self-antigen $\mathrm{s}^{23}$ or development of immunity to foreign epitopes that cross react with self-antigens. ${ }^{24}$ It is 
interesting to consider here that COPD shares many clinical and pathophysiological characteristics of several autoimmune diseases such as rheumatoid arthritis (RA). ${ }^{23}$ Firstly, smoking is a risk factor for both COPD ${ }^{9}$ and RA. ${ }^{25}$ Secondly, once initiated, the inflammatory response of RA is self-perpetuating. ${ }^{26}$ To some extent, this may be analogous to the continued airway inflammation seen after cessation of smoking. ${ }^{10-12}$ Thirdly, exacerbations occur both in RA and COPD. Yet, while in COPD they are "explained" by external factors such as airway infection and air pollution, ${ }^{20}$ in RA they are considered an integral part of the disease process, characterised by $\mathrm{T}$ cells sensitised to either cartilage epitopes ${ }^{27}$ and/or degradation products of intestinal bacteria that mimic them, ${ }^{26}$ homing to the synovium and contributing to the maintenance-or amplification of the inflammatory process. Finally, similarities between the inflammatory cells (neutrophils, macrophages, $\mathrm{T}$ lymphocytes) and cytokines (tumour necrosis factor (TNF)- $\alpha$, interleukin (IL)-6, IL-8) involved in the pathogenesis of $\mathrm{RA}^{28-30}$ and $\mathrm{COPD}^{67}$ are remarkable.

\section{THE HYPOTHESIS}

We propose that an acquired immune response to newly created or altered epitopes is an essential component in the pathogenesis of COPD. This hypothesis implies the loss of tolerance to selfepitopes and would qualify COPD as an "autoimmune" disease induced by cigarette smoking. If true, this hypothesis may help to answer the questions posed above-namely, why only some smokers develop the disease, why lung inflammation persists after smoking cessation and, perhaps, the underlying pathobiology of some exacerbations of COPD. To support this hypothesis we will review the evidence for alterations of the "normal" components of the immune response in COPD and propose several (testable) mechanisms by which autoimmunity may arise in a disease caused by a clearly identified external agent (tobacco smoking).

\section{IMMUNE RESPONSES IN COPD}

The normal immune response comprises the innate (natural) and acquired (adaptive) responses. ${ }^{31}$ The innate response involves phagocytic cells (neutrophils, macrophages), cells that release inflammatory mediators (mast cells, eosinophils), and natural killer cells. ${ }^{31}$ The acquired response requires the proliferation of $\mathrm{B}$ and $\mathrm{T}$ cells after antigen presentation by specialised cells (macrophages and dendritic cells). ${ }^{31}$ Many elements of both types of response are abnormal in COPD. ${ }^{67}$
Implicitly, although not explicitly, the innate immune response has long been considered as dominating the pathogenesis of COPD, since the traditional proteinase-antiproteinase theory of the pathogenisis of $\mathrm{COPD}^{32}$ requires the participation of neutrophils and macrophages, which are both prominent elements of such a response. ${ }^{31}$ However, the role of the acquired response has largely been ignored. Yet, there is some evidence to support the contention that there is increased acquired immunity in COPD: (1) both helper (CD4+) and cytotoxic T lymphocytes (CD8+) accumulate in the lung parenchyma of patients with $\mathrm{COPD}^{6}{ }^{7}$; (2) B lymphocytes form the core of the so-called bronchus-associated lymphoid tissue (BALT) which has been shown to be significantly increased in smokers ${ }^{33}$ and in patients with $\mathrm{COPD}^{34}$; (3) smoking is associated with an expansion of the population of antigen presenting cells on the epithelial surface of the lower respiratory tract $^{35}$; and (4) preliminary data from our laboratory suggest an increased prevalence of antinuclear antibody titres in patients with COPD compared with smokers with normal lung function (unpublished data). Whether these abnormalities represent a response to smoking or play a pathogenic role in the development of COPD will have to be explored in future studies.

\section{POTENTIAL MECHANISMS}

An aberrant acquired immune response can result from either a defect in the selection, regulation or death of immune cells ( $\mathrm{T}$ or B lymphocytes) or from the generation of new (self or foreign) antigens. ${ }^{23}$ Both possibilities could operate in COPD through several different mechanisms. Tobacco smoking (the main risk factor for COPD) modulates the proliferation ${ }^{36} 37$ and death pathways of lymphocytes, ${ }^{38}$ can generate new epitopes by either directly oxidising existing proteins ${ }^{39} 40$ or indirectly by interfering with the clearance of apoptotic cells, ${ }^{41}$ thus exposing anatomically sequestered intracellular antigens to the immune system, ${ }^{23} 42$ and upregulates the population of antigen presenting cells in the lungs ${ }^{35}$ thus amplifying the capacity to process new antigens. In addition, several factors frequently associated with COPD may also contribute to an acquired immune response. For instance, chronic airway bacterial colonisation is common in COPD. ${ }^{43} 44$ In RA intestinal bacteria have been shown to be a source of new antigens contributing to the maintenance of the inflammatory process. ${ }^{26}{ }^{45}$ It is therefore possible that chronic airway colonisation by bacteria may exert a similar effect in COPD. Viral infections ${ }^{46} 47$ and oxidative stress created by environmental particles ${ }^{48}$ could also contribute to the development of new/altered epitopes. In summary, there are many different potential mechanisms that can theoretically boost an acquired immune response in COPD. The challenge is now to design the appropriate studies (human and experimental) to prove (or disprove) this hypothesis.

\section{IMPLICATIONS}

The current view is that chronic inflammation is a key pathogenic element in COPD because it contributes to the decline in lung function that characterises the disease. ${ }^{5}$ Available antiinflammatory treatment (that is, inhaled steroids) does not have a consistent effect on the inflammation in COPD ${ }^{49}$ New therapeutic measures are therefore urgently needed. ${ }^{4}$ This is particularly important if the airspace inflammation in COPD continues despite quitting smoking. ${ }^{10-12}$ If true, the hypothesis proposed here should lead to the development of new therapeutic strategies aimed at immunomodulation. These may both halt the progression of the disease and prevent the episodes of exacerbation. If so, this would contribute enormously to improving the well being of patients with COPD and to decreasing the enormous healthcare burden associated with this disease. ${ }^{20}$

\section{CONCLUSIONS}

We have developed a hypothesis that, by reconciling separate observations, may point towards a new and potentially relevant mechanism in the pathogenesis of COPD. However, we recognise that there is, as yet, insufficient evidence to support it. For instance, some of the inflammatory abnormalities described in COPD—such as the expansion of the bronchial associated lympoid tissue and the antigen presenting cell populationmay in fact be a physiological adaptation rather than a pathological one. However, we think that there is enough indirect circumstantial evidence to explore this hypothesis further. Indeed, if there was firm evidence to support (or disprove) it, it would not longer be a hypothesis! We hope that researchers in this field agree with us in that it may be worth exploring. If so, we would suggest that studies aimed at detecting the presence of autoantigens, identifying potential epitopes and/or determining any potential relationship between COPD and HLA typing, among others, may eventually provide useful information for the benefit of patients with COPD. 


\section{ACKNOWLEDGEMENTS}

The authors thank the Scottish weather for keeping Dr Agusti indoors and working on this hypothesis when he would otherwise be out enjoying the Festival. The authors also thank Drs Ian McInnes and Robin Stevenson (Department of Medicine in Glasgow University) and Dr Sarah Howie (Department of Pathology in Edinburgh University) for helpful discussions over this hypothesis. ABEMAR and the Fundacíó Catalana de Neumologia (FUCAP) supported the sabbatical leave of $\mathrm{Dr}$ Agusti at the University of Edinburgh during the summer of 2001. Ken Donaldson is the Transco British Lung Foundation Fellow in Air Pollution and Respiratory Health.

Thorax 2003;58:832-834

\section{Authors' affiliations}

A Agustí, Servei de Pneumologia, Hospital Universitari Son Dureta. Palma de Mallorca, Spain

W MacNee, K Donaldson, ELEGI Laboratory, University of Edinburgh, UK

M Cosio, McGill University, Montreal, Canada

Supported in part by ABEMAR and FUCAP.

Correspondence to: Professor W MacNee, ELEGI Colt Research Laboratory, Wilkie Building, University of Edinburgh Medical School. Teviot Place, Edinburgh EH89AG; wmacnee@ed.ac.uk

\section{REFERENCES}

1 Murray CCJL, Lopez AD. Mortality by cause for eight regions of the world: global burden of disease study. Lancet 1997:1269-76.

2 Okubadejo AA, Jones PW, Wedzicha JA. Quality of life in patients with chronic obstructive pulmonary disease and severe hypoxaemia. Thorax 1996;51:44-7.

3 Seemungal TA, Donaldson GC, Paul EA, et al. Effect of exacerbation on quality of life in patients with chronic obstructive pulmonary disease. Am J Respir Crit Care Med 1998;157/5 Pt 1):1418-22.

4 Barnes PJ. Chronic obstructive pulmonary disease. N Engl J Med 2000;343:269-80.

5 Pauwels RA, Buist AS, Calverley PM, et al. Global strategy for the diagnosis, management, and prevention of chronic obstructive pulmonary disease. NHLBI/WHO Global Initiative for Chronic Obstructive Lung Disease (GOLD) Workshop summary. Am J Respir Crit Care Med 2001; 163:1256-76.

6 Cosio MG, Guerassimov A. Chronic obstructive pulmonary disease. Inflammation of small airways and lung parenchyma. Am J Respir Crit Care Med 1999; 160(5 Pt 2):S21-5.

7 Saetta M, Turato G, Maestrelli $P$, et al. Cellular and structural bases of chronic obstructive pulmonary disease. Am J Respir Crit Care Med 2001;163:1304-9.

8 Shapiro SD. End-stage chronic obstructive pulmonary disease. The cigarette is burned out but inflammation rages on. Am J Respir Crit Care Med 2001;164:339-40.

9 Fletcher C, Peto R. The natural history of chronic airflow obstruction. BMJ 1977:1:1645-8.

10 Turato G, Di Stefano A, Maestrelli P, et al. Effect of smoking cessation on airway inflammation in chronic bronchitis. Am J Respir Crit Care Med 1995;152(4 Pt 1):1262-7.

11 Rutgers SR, Postma DS, ten Hacken NH, et al Ongoing airway inflammation in patients with COPD who do not currently smoke. Thorax 2000;55:12-8.

12 Retamales I, Elliot MW, Meshi B, et al. Amplification of inflammation in emphysema and its association with latent adenoviral infection. Am J Respir Crit Care Med 2001;164:469-73.

13 Van Parijs L, Abbas AK. Homeostasis and selftolerance in the immune system: turning lymphocytes off. Science 1998;280:243-8.

14 Kamradt T, Mitchison NA. Tolerance and autoimmunity. N Engl J Med 2001;344:655-64

15 Seemungal TA, Donaldson GC, Bhowmik A, et al. Time course and recovery of exacerbations in patients with chronic obstructive pulmonary disease. Am J Respir Crit Care Med 2000;161:1608-13.

16 Connors AF Jr, Dawson NV, Thomas C, et al. Outcomes following acute exacerbation of severe chronic obstructive lung disease. Am J Respir Crit Care Med 1996;154:959-67.

17 Bhowmik A, Seemungal TA, Sapsford RJ, et al. Relation of sputum inflammatory markers to symptoms and lung function changes in COPD exacerbations. Thorax 2000;55:114-20.

18 Roland M, Bhowmik A, Sapsford RJ, et al. Sputum and plasma endothelin-1 levels in exacerbations of chronic obstructive pulmonary disease. Thorax 2001;56:30-5

19 Aaron SD, Angel JB, Lunau M, et al. Granulocyte inflammatory markers and airway infection during acute exacerbation of chronic obstructive pulmonary disease. Am J Respir Crit Care Med 2001; 163:349-55.

20 Ekberg-Jansson A, Larsson S, Lofdahl CG. Preventing exacerbations of chronic bronchitis and COPD. BMJ 2001;322:1259-61.

21 Gompertz S, O'Brien C, Bayley DL, et al. Changes in bronchial inflammation during acute exacerbations of chronic bronchitis. Eur Respir J 2001;17:1112-9.

22 Sunyer J. Urban air pollution and chronic obstructive pulmonary disease: a review. Eur Respir J 2001;17:1024-33.

23 Davidson A, Diamond B. Autoinmmune diseases. N Engl J Med 2001:345:340-50.

24 Albert L, Inman RD. Molecular mimicry and autoimmunity. N Engl J Med 1999;341:2068-74.

25 Hutchinson D, Shepstone L, Moots R, et al. Heavy cigarette smoking is strongly associated with rheumatoid arthritis (RA), particularly in patients without a family history of RA. Ann Rheum Dis 2001:60:223-7.

26 Toivanen $\mathbf{P}$. From reactive arthritis to rheumatoid arthritis. J Autoimmun $2001 ; 16: 369-71$

27 Guerassimov A, Zhang Y, Banerjee S, et al. Autoimmunity to cartilage link protein in patients with rheumatoid arthritis and ankylosing spondylitis. J Rheumatol 1998:25:1480-4

28 Arend WP. Physiology of cytokine pathways in rheumatoid arthritis. Arthritis Rheum 2001:45:101-6.

29 Koetz K, Bryl E, Spickschen K, et al. T cell homeostasis in patients with rheumatoid arthritis Proc Natl Acad Sci USA 2000;97:9203-8.

30 Pitzalis C, Kingsley G, Murphy J, et al. Abnormal distribution of the helper-inducer and suppressorinducer T lymphocyte subsets in the rheumatoid joint. Clin Immunol Immunopathol 1987;45:252-8

31 Delves PJ, Roitt IM. The immune system. First of two parts. N Engl J Med 2000;343:37-49.

32 Shapiro SD. Evolving concepts in the pathogenesis of chronic obstructive pulmonary disease. Clin Chest Med 2000;21:621-32.

33 Richmond I, Pritchard GE, Ashcroft T, et al. Bronchus associated lymphoid tissue (BALT) in human lung: its distribution in smokers and nonsmokers. Thorax 1993;48:1130-4.

34 Bosken CH, Hards J, Gatter K, et al. Characterization of the inflammatory reaction in the peripheral airways of cigarette smokers using immunocytochemistry. Am Rev Respir Dis 1992;145(4 Pt 1):911-7.

35 Casolaro MA, Bernaudin JF, Saltini C, et al. Accumulation of Langerhans' cells on the epithelial surface of the lower respiratory tract in normal subjects in association with cigarette smoking. Am Rev Respir Dis 1988;137:406-11.

36 Vignes S, Oksenhendler E, Quint L, et al. Polyclonal B lymphocytosis and hyper-lgM: immunodeficiency and/or benign lymphoid proliferation associated with tobacco? Rev Med Interne 2000;21:236-41.

37 Chan MA, Benedict SH, Carstairs KC, et al. Expansion of $B$ lymphocytes with an unusual immunoglobulin rearrangement associated with atypical lymphocytosis and cigarette smoking. Am J Respir Cell Mol Biol 1990;2:549-52

38 Suzuki N, Wakisaka S, Takeba Y, et al. Effects of cigarette smoking on Fas/Fas ligand expression of human lymphocytes. Cell Immunol 1999; 192:48-53.

39 Rahman I, MacNee W. Oxidative stress and regulation of glutathione in lung inflammation. Eur Respir J 2000;16:534-54.

40 Cerami C, Founds $\mathrm{H}$, Nicholl I, et al. Tobacco smoke is a source of toxic reactive glycation products. Proc Natl Acad Sci USA 1997:94:13915-20.

41 Finkelstein El, Nardini M, van der Vliet $A$ Inhibition of neutrophil apoptosis by acrolein: a mechanism of tobacco- related lung disease? Am J Physiol Lung Cell Mol Physiol 2001;281:L732-9.

42 Majo J, Ghezzo H, Cosio MG. Lymphocyte population and apoptosis in the lungs of smokers and their relation to emphysema. Eur Respir J 2001;17:946-53.

43 Monsó E, Ruiz J, Rosell A, et al. Bacterial infection in chronic obstructive pulmonary disease - a study of stable and exacerbated outpatients using the protected specimen brush. Am J Respir Crit Care Med 1995; 152:1316-20

44 Zalacaín R, Sobradillo V, Amilibia J, et al. Predisposing factors to bacterial coloniozation in chronic obstructive pulmonary disease. Eur Respir J 1999;13:343-8.

45 Toivanen A. Bacteria-triggered reactive arthritis: implications for antibacterial treatment. Drugs 2001;61:343-51

46 Diaz PT, King MA, Pacht ER, et al. Increased susceptibility to pulmonary emphysema among HIV-seropositive smokers. Ann Intern Med 2000;132:369-72.

47 Hogg JC. Latent adenoviral infection in the pathogenesis of emphysema. Chest 2000;117/5 Suppl 1):282S-5S

48 Li XY, Gilmour PS, Donaldson K, et al. Free radical activity and pro-inflammatory effects of particulate air pollution (PM10) in vivo and in vitro. Thorax 1996;51:1216-22.

49 Barnes NC. Inhaled steroids in COPD. Lance 1998:351:766-7. 